respectively, correctly identified a maximum number of alcoholic beverages one can ingest before driving. In the two cities, $40 \%$ reported exposure to a wide-spread campaign; accurate knowledge of campaign phrases ranged from $1-60 \%$ and $45 \%$ reported resulting attitude/behaviour change. 30-35\% had experienced individualised intervention, and $50 \%$ reported attitude/behaviour change as a result.

Significance/Contribution to the Field Students self-reported having had exposure to various targeted road safety interventions in both cities; $\sim 50 \%$ of those noted resulting attitude/behaviour changes as a result of these exposures. There was a marked knowledge deficit regarding the number of alcoholic drinks one could consume prior to driving safely. This study highlights an opportunity both for targeted education and continued intense interventions in order to reduce DWI in Mexican youth.

\section{2 EVALUATING THE REACH OF YOUTH-FOCUSED DRINKING AND DRIVING REDUCTION INTERVENTIONS IN TWO MEXICAN CITIES}

doi:10.1136/injuryprev-2012-040590r.2

\author{
${ }^{1} \mathrm{MM}$ Hijar, ${ }^{1} \mathrm{D}$ Santoyo, ${ }^{2} \mathrm{~A}$ Chandran, ${ }^{3} \mathrm{R}$ Pérez-Núñez, ${ }^{1} \mathrm{JC}$ Lunnen, ${ }^{2} \mathrm{AA}$ Hyder. \\ ${ }^{1}$ Fundación Entornos A.C., México; ${ }^{2} J o h n s$ Hopkins International Injury Research Unit, \\ USA; ${ }^{3}$ nstituto Nacional de Salud Pública, México
}

Background Road crashes are a leading cause of death for Mexicans aged 15-34 years. This population is one of the targets for drinking and driving (DWI) related campaigns and interventions instituted as part of a large road safety intervention programme.

Aims/Objectives/Purpose To evaluate the reach of DWI reduction interventions in a random sample of high school and university students from Guadalajara-Zapopan and León by assessing their knowledge related to DWI, their awareness of various interventions and campaigns, and their self-reported behaviour change as a result.

Methods A close-ended questionnaire was applied in-person to a random sample of students at both public and private institutions in October-December 2011.

Results/Outcome A total of 5114 students were surveyed: 2478 in Guadalajara-Zapopan, and 2636 in León. Only $17.3 \%$ and 14.3\%, 